\title{
CO oxidation over gold nanocatalyst confined in mesoporous silica
}

\author{
Yu-Shan Chi ${ }^{a}$, Hong-Ping Lin ${ }^{\mathrm{b}}$, Chung-Yuan $\mathrm{Mou}^{\mathrm{a}, *}$ \\ ${ }^{a}$ Department of Chemistry and Center of Condensed Matter Science, National Taiwan University, Taipei 106, Taiwan \\ ${ }^{\mathrm{b}}$ Department of Chemistry, National Cheng Kung University, Tainan, Taiwan
}

Received 17 May 2004; received in revised form 21 January 2005; accepted 24 January 2005

Available online 13 February 2005

\begin{abstract}
$\mathrm{Au}$ nanoparticles embedded within mesoporous silica particles have been prepared and used as catalysts for CO oxidation. The silane APTS $\left(\mathrm{H}_{2} \mathrm{~N}\left(\mathrm{CH}_{2}\right)_{3}-\mathrm{Si}(\mathrm{OMe})_{3}\right)$ was used to surface-functionalize mesoporous silica in a direct method. The functionalized mesoporous silica was used to absorb the gold precursor $\mathrm{AuCl}_{4}{ }^{-}$and gold nanoparticles were formed inside the nanochannels after chemical reduction. The catalysts were activated by calcinations, followed with hydrogen reduction at $600{ }^{\circ} \mathrm{C}$. MCM-41, MCM- 48 and SBA-15 were used as the supports to prepare Au nanoparticles, resulting in different particle sizes of Au. The catalysts are active in the oxidation of carbon monoxide, reaching activity values as high as $7.0 \times 10^{-3} \mathrm{mmol} \mathrm{g}_{\text {cat }}^{-1} \mathrm{~s}^{-1}$ at $353 \mathrm{~K}$. The conversion of CO increases with decreasing size of gold nanoparticles.
\end{abstract}

(C) 2005 Elsevier B.V. All rights reserved.

Keywords: Gold; Nanotechnology; Heterogeneous catalysis; Oxidation; Mesoporous silica

\section{Introduction}

Metal nanoparticles supported on metal oxides shows many interesting types of catalytic behavior [1]. They cover a size range intermediate between the atomic/molecular regime on the one hand and the bulk on the other hand. Due to recent rapid advances in fabricating and characterizing [2] of nanocatalysts, there is a high interest in studying the chemical reactivity of the nanocatalysts and the size effects [3].

Bulk gold is a noble metal. However, Haruta and Date [4] discovered that well-dispersed nano-sized gold catalysts are extremely active for $\mathrm{CO}$ oxidation. The optimum size of the Au nanocatalyst seems to be around $3 \mathrm{~nm}[5,6]$. Its catalytic behavior is rather complex, depending on the size of $\mathrm{Au}$ $[5,6]$, the kind of support $[7,8]$ and the methods of catalyst preparation [9]. Therefore, it is highly desirable to synthesize uniformly sized Au nanoparticles supported on well-defined porous materials with high loading [10].

\footnotetext{
* Corresponding author. Tel.: +88623366 5251; fax: +886223660954. E-mail address: cymou@ntu.edu.tw (C.-Y. Mou).
}

In this paper, we employ the well-studied mesoporous silica as supporting host to confine the Au nanoparticle and to study its catalytic effect on $\mathrm{CO}$ oxidation. The materials possess the advantages of high-surface area $\left(\sim 1000 \mathrm{~m}^{2} / \mathrm{g}\right)$ and tunable uniform pore size $(2.0-10.0 \mathrm{~nm})$ [11]. There have been large varieties of pore systems [11], morphologies, [12] and surface functionalizations [13]. The strong confinement of the pore system would provide a uniform distribution of the Au nanoparticles [14-16]. Moreover, because there is the further possibility of surface modification to accommodate other functionality, combining $\mathrm{Au}$ nanoparticles and mesoporous silica could produce an advanced catalyst system for versatile applications [10].

For gold/metal oxide catalytic systems, it is generally believed that silica is a poor support, its use resulting in low catalytic activity [7,17]. However, the reason is not clear: is it because the size of Au nanoparticle tends to be bigger on a silica surface or because the catalyst/support interaction is poor? It is not easy to separate the above roles in the catalytic $\mathrm{CO}$ oxidation on a system of gold nanoparticles supported on metal oxides [18]. For catalytic activity, there are two factors that need to be considered: the particle size effect and the metal-support interaction $[3,4,17]$. Both phenomena are 
documented [3,4]. For a silica surface, it is known that gold and silica surface interact weakly. Thus, one may use silica support to study the 'pure' size effect [17]. However, the silica support employed is often silica gel, where $\mathrm{Au}$ nanoparticles are generally mobile after high temperature treatment, and form large conglomerates. In view of the adverse effect of sintering on the catalytic activity, it needs to be prevented or delayed. One approach to suppress sintering is to confine the gold nanocatalyst within the nanopores of mesoporous silica materials such that the optimum size for catalysis may be obtained. Mesoporous materials may serve as an excellent support to confine the size of nanoparticles [19].

We would like to have a silica support with controlled uniform pore system, where the size of the Au nanoparticle is limited by the pore. This desire can be met by embedding Au nanoparticles within the nanopores of mesoporous silica materials. There have been several recent reports on embedding $\mathrm{Au}$ nanoparticles within mesoporous silica [14-16,20,21]. However, the reported nanomaterials systems have not yet been tested on catalytic applications. There are only very few studies on the catalysis of $\mathrm{CO}$ oxidation for such kind of mesostructured system [22,23]. Our purpose in this paper is to report a synthesis of the $\mathrm{Au}$ nanoparticles confined in the nanochannels of mesoporous silica and the $\mathrm{CO}$ oxidation activity.

For preparing a supported gold catalyst system, there are at present several approaches. The impregnation method, the chemical vapor deposition and depositionprecipitation (DP) process using various Au precursors are the three most common strategies to prepare $\mathrm{Au}$ nanocatalysts. The impregnation method has been shown to be not effective [24]. Deposition-precipitation process applied to silica does not give good catalytic activity compared with other surfaces with redox behavior (for example, $\mathrm{Fe}_{2} \mathrm{O}_{3}$ ) [8,25]. Chemical vapor deposition (CVD) method has been applied to MCM-41 materials and resulting in surprisingly active catalyst [26]; but the volatile $\mathrm{Au}$ precursor is very expensive.

On the other hand, chemical reduction methods using a standard reductant such as hydrogen or $\mathrm{NaBH}_{4}$ have often been employed in making surface protected Au nanoparticles with great success [27]. The size and loading of the pre-formed nanoparticles can be better controlled [28,29]. However, in this approach, the loading and activation of the colloid is often a problem. In our previous works [22], we prepared the stable Au-CTAB aqueous solution after a simple solution reduction of tetrachloroaurates $\left(\mathrm{HAuCl}_{4}\right)$. Then the pre-formed $\mathrm{Au}$ nanoparticles and surfactantcontaining aqueous solution were used directly for templating the formation of mesoporous material, in which the Au nanoparticles were embedded. But in this method, the nanoparticles are found to be larger than the channel size after calcination.

In this paper, we take another approach by using surfacefunctionalized mesoporous silica to adsorb the gold precursor and do the chemical reduction afterwards [30,31]. In this way, the rigid and mono-disperse pore system would limit the size of the gold nanoparticles better. We will show that its catalytic activity in $\mathrm{CO}$ oxidation is surprisingly high, compared with the results from catalysts made with the standard precipitation-deposition method. In order to absorb a fairly high level of gold inside the pores, we employ a direct surface modification method developed in our laboratory [13,32].

\section{Experimental}

\subsection{As-synthesized mesoporous silica}

\subsection{1. $M C M-41$}

A desired amount of sodium silicate was added to a mixture of $1.53 \mathrm{~g}$ cetyltrimethylammonium bromide $\left(\mathrm{C}_{16} \mathrm{TMAB}\right)$ and $11.0 \mathrm{~g}$ water that gave a clear solution. After a neutralization procedure (the final $\mathrm{pH}$ value of the gel solution is about 8-10), the solution was stirred for $2 \mathrm{~h}$ at $40{ }^{\circ} \mathrm{C}$. A white precipitate gel solution was formed. The molar ratios of the gel composites are 1.0 $\mathrm{SiO}_{2}: 0.71 \quad \mathrm{C}_{16}$ TMAB:0.6 NaOH:0.24 $\mathrm{H}_{2} \mathrm{SO}_{4}: 300 \quad \mathrm{H}_{2} \mathrm{O}$. Then, the gel solution was transferred to an autoclave, undergoing hydrothermal reaction at $100{ }^{\circ} \mathrm{C}$ for $48 \mathrm{~h}$. Finally, filtration, washing, and drying give the assynthesized MCM-41.

\subsection{2. $M C M-48$}

Here, $\quad 1.37 \mathrm{~g}$ cetyltrimethylammonium bromide $\left(\mathrm{C}_{16} \mathrm{TMAB}\right)$ and $12.0 \mathrm{~g}$ water were mixed to give a clear solution. $\mathrm{NaOH}$ solution was added to adjust the final $\mathrm{pH}$ value to about $8-10$, and then TEOS was added. The mixture was stirred for $2 \mathrm{~h}$ at $30{ }^{\circ} \mathrm{C}$ and a white precipitate gel solution were formed. The molar ratios of the gel composites are $1.0 \mathrm{SiO}_{2}: 0.56 \mathrm{C}_{16}$ TMAB:0.48 NaOH: $100 \mathrm{H}_{2} \mathrm{O}$. The rest of the procedure is the same as that of MCM- 41 .

\subsection{3. $S B A-15$}

Ten grams of $\mathrm{P}_{123}$ and $300 \mathrm{~g}$ of water were mixed and stirred at $40{ }^{\circ} \mathrm{C}$ to obtain a clear solution to which $40 \mathrm{ml}$ of $18 \mathrm{~N} \mathrm{HCl}$ solution and $23 \mathrm{~g}$ of TEOS were added to the solution to obtain precipitates. The work-up procedure is the same as that of MCM-41.

\subsubsection{To prepare the acid-treated mesoporous silica}

In order to use the direct modification method [13,32], one must transform the surface condition of the silica into acidic form. The dried as-synthesized MCM-41 and MCM-48 samples were acidified with nitric acid solution $(\mathrm{pH}<1)$, where the weight ratio of sample to acidic solution is 1:50. The mixture was then stirred at room temperature for 1-2 days. After filtration and drying, the acid-treated MCM-41 and MCM-48 samples were obtained. 


\subsubsection{To prepare surface-modified mesoporous silica}

A proper amount of SBA-15, or acid-treated mesoporous MCM-41 and MCM-48, was immersed in an ethanol solution of the silane APTS $\left(\mathrm{H}_{2} \mathrm{~N}\left(\mathrm{CH}_{2}\right)_{3}-\mathrm{Si}(\mathrm{OMe})_{3}\right)$ and refluxed for $3-6 \mathrm{~h}$ at about $70{ }^{\circ} \mathrm{C}$. The products were recovered by filtration, washed with a large amount of ethanol and dried.

\subsubsection{To prepare the Au-containing mesoporous silica}

A proper amount of the surface-functionalized mesoporous silica was added to the tetrachloroaurate $\left(\mathrm{HAuCl}_{4}\right)$ solution. The solution was reduced with sodium boronhydride $\left(\mathrm{NaBH}_{4}\right)$ aqueous solution dropwise at room temperature: the reddish brown Au nanoparticles embedded in mesoporous silica that formed were collected.

\subsubsection{Catalysis}

Prior to the catalysis tests, the catalysts are activated by calcinations under air at $560{ }^{\circ} \mathrm{C}$. Then the catalysts were heated to $600{ }^{\circ} \mathrm{C}$ under $\mathrm{H}_{2} / \mathrm{N}_{2}$ flow and held for $1 \mathrm{~h}$, and cooled to room temperature under $\mathrm{N}_{2}$ flow. Oxidation of carbon monoxide was carried out in a quartz-tubular reactor (7 mm i.d.) under atmospheric pressure. Catalysts with a fixed amount of gold $(20 \mathrm{mg})$ were used for the reaction. Two gases: $32.7 \mathrm{ml} / \mathrm{min}$ of air and $0.33 \mathrm{ml} / \mathrm{min}$ of carbon monoxide (99.3\%, CP grade, Linde Division, Union Carbide) were purified by $4 \AA$ molecular sieves, then mixed and flowed into the reactor for the reaction. The water vapor content in the reactant stream is no more than $4 \mathrm{ppm}$. A Shimadzu GC-8A gas chromatograph was used for the analysis of the composition in the reactor out-stream. A Carboxy-2000 column was employed for the separation of carbon dioxide, carbon monoxide, nitrogen and oxygen.

\subsubsection{Characterization}

The UV-vis spectra were recorded on a Hitachi U-3010 UV-VIS Spectrophotometer at ambient temperature. The electron microscopic images of the Au nanoparticles and mesoporous aluminosilicate were recorded on a Philip CM200 high-resolution transmission electron microscope with an operating voltage of $200 \mathrm{keV}$. The powder X-ray diffraction patterns (XRD) were taken on a Scintag X1 diffractometer using $\mathrm{Cu} \mathrm{K} \alpha$ radiation. $\mathrm{N}_{2}$ adsorptiondesorption isotherms were obtained at $77 \mathrm{~K}$ on a Micromeritics ASAP 2010 apparatus, and the pore size distribution was calculated from the nitrogen adsorption isotherm using the BJH (Barrett-Joyner-Halenda) method. The XPS spectra were obtained with a VG ESCALAB 250 equipped with a monochromated $\mathrm{Al} \mathrm{K} \alpha$ radiation source under a residual pressure of $\sim 10^{-9}$ Torr. For charge compensation, a flood gun with variable electron voltage $(6-8 \mathrm{eV})$ was used.

\section{Results}

It is known that the precursors of gold nanoparticles, $\mathrm{AuCl}_{4}{ }^{-}$, and the amino functional group have a good chemical interaction. We thus grafted the aminosilane APTS (aminopropyltrimethoxysilane) on the mesoporous silica. In order to monitor the amount of the grafted silanes, we employed elemental analysis to determine the quantity of organic amino group. In Table 1, we list the textural properties of the three mesoporous materials, MCM-41, MCM-48, and SBA-15. We include the pore size and pore volume after surface modification with APTS and after loading gold nanoparticles. For the purpose of comparison, we also include textural properties for the calcined mesoporous materials, although we directly functionalize APTS on as-synthesized mesoporous materials, instead of calcining the samples. From Table 1, we find that, after surface modification, the pore size and pore volume of the mesoporous materials are somewhat reduced. It means that the organic silane is predominantly grafted on the pore wall of the mesoporous silica and that there is little poreblocking. After loadings of Au, they are further reduced. For SBA-15, there seems to be enough pore-blocking to lead to a more reduced pore volume. According to the elemental analyses, the density of the organic functional group in the MCM-41 grafted product is $3.36 \mathrm{mmol} / \mathrm{g}$. In order to compare their catalytic activities, we control the Au-loading on all samples to be the same at $4 \%$.

We then discuss the process of gold loadings. For simplicity, we discuss the process on MCM-41. The other two supports behave similarly. The mesoporous silica after modification could adsorb the gold precursor $\mathrm{AuCl}_{4}{ }^{-}$easily. A yellow-colored material was formed within few seconds after mixing the $\mathrm{AuCl}_{4}{ }^{-}$solution and the modified mesoporous silica. Fig. 1a(A) shows for MCM-41 that strong low-angle peaks at $2 \theta=1.5^{\circ}-5^{\circ}$ appear; these indicate that the mesostructure of mesoporous silica is not destroyed after adsorption of $\mathrm{AuCl}_{4}{ }^{-}$ion. The $\mathrm{Au}$ nanoparticles are not yet reduced at this stage, so there

Table 1

The physical properties of various mesoporous silicates

\begin{tabular}{|c|c|c|c|c|c|c|c|c|c|}
\hline & $\mathrm{MCM}-41 \mathrm{C}^{\mathrm{a}}$ & MCM-48C & SBA-15C & $\mathrm{MCM}-41 \mathrm{M}^{\mathrm{b}}$ & MCM-48M & SBA-15M ${ }^{b}$ & $\mathrm{MCM}-41 \mathrm{Au}^{\mathrm{c}}$ & MCM-48 Au ${ }^{\mathrm{c}}$ & $\mathrm{SBA}-15 \mathrm{Au}^{\mathrm{c}}$ \\
\hline S.A. $\left(\mathrm{m}^{2} / \mathrm{g}\right)$ & 1005 & 1322 & 510 & 871 & 728 & 260 & 467 & 468 & 275 \\
\hline Pore size (nm) & 2.9 & 2.3 & 5.5 & 1.9 & 1.73 & 5.4 & 1.9 & 1.8 & 5.2 \\
\hline Pore volume $\left(\mathrm{cm}^{3} / \mathrm{g}\right)$ & 0.874 & 0.634 & 0.46 & 0.364 & 0.385 & 0.291 & 0.243 & 0.256 & 0.351 \\
\hline
\end{tabular}

${ }^{\text {a }}$ Calcined at $560{ }^{\circ} \mathrm{C}$.

b Modified with APTS.

c Adsorbed $\mathrm{AuCl}_{4}{ }^{-}$, reduced by $\mathrm{NaBH}_{4}$ and then calcined at $560{ }^{\circ} \mathrm{C}$. 


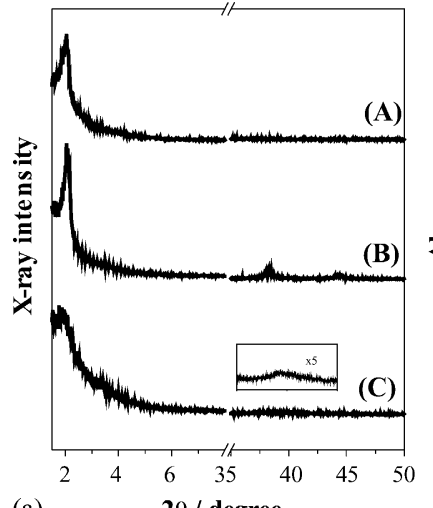

(a)

$2 \theta /$ degree

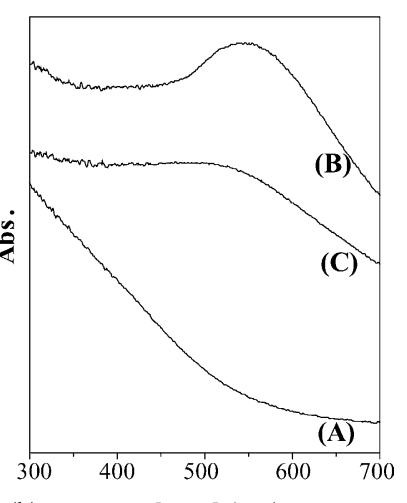

(b) wavelength(nm)

Fig. 1. (a) XRD pattern and (b) solid-state UV-vis of Au-loaded MCM-41 after being modified with APTS. (A) $\mathrm{AuCl}_{4}{ }^{-}$adsorbed without reduction, (B) $\mathrm{AuCl}_{4}{ }^{-}$adsorbed and heated in air $\left(100{ }^{\circ} \mathrm{C}\right)$ and (C) $\mathrm{AuCl}_{4}{ }^{-}$adsorbed and reduced with $\mathrm{NaBH}_{4}$.

are not any XRD peaks at high angles of $38.4^{\circ}$ and $44.6^{\circ}$ ascribed to gold.

After the wet-loaded mesoporous silica was thermally reduced in an oven at $100{ }^{\circ} \mathrm{C}$ for $3 \mathrm{~h}$, Au nanoparticles were formed. Curve (B) in Fig. 1a shows that there exists some high-angle XRD peak characteristics of Au nanoparticles. The corresponding UV-vis absorption in Fig. $1 b(B)$ gives a broad peak at $550 \mathrm{~nm}$, which is due to the surface plasmon resonance (SPR) band of the Au nanoparticles. Although Au nanoparticles may be reduced in this way, its size appears to be above $5 \mathrm{~nm}$ as one can judge both from the sharper SPR band and the relatively sharp XRD diffraction peak. The nanoparticles are not well confined in the pore system of this material. Instead, many large particles appear outside the pores. Also we note that the low-angle peak of Fig. 1a(B) is as strong as that in Fig. 1 a(A). The pore system of the mesoporous silica is essentially preserved.

When $\mathrm{NaBH}_{4}$ was used as the reductant, the resulting $\mathrm{XRD}$ and UV-vis absorption patterns are given as curve (C) in Fig. 1a and 1b. The high-angle XRD peak of Au nanoparticles is broader. The sizes of Au nanoparticles were very small, about $2 \mathrm{~nm}$ as estimated from the Scherrer equation. At the same time, the UV-vis absorption shows a broad SPR band, indicating the very small size of $\mathrm{Au}$

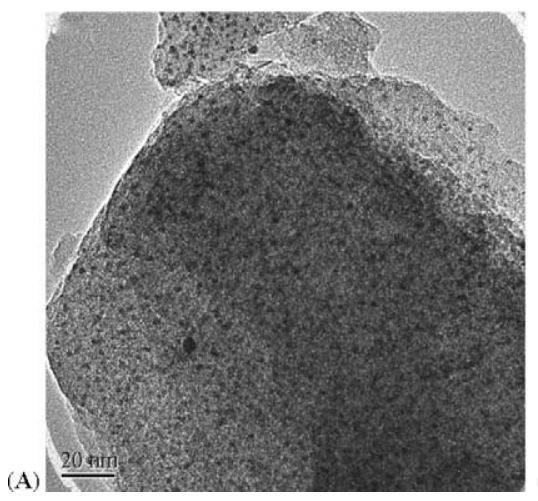

nanoparticles. The low-angle XRD peaks are weaker, meaning that the pore structure is not as well ordered as before; the reduced $\mathrm{Au}$ nanoparticles inside the pores of mesoporous silica may distort somewhat the mesostructure of MCM-41.

In order to confirm that the $\mathrm{Au}$ nanoparticles were reduced completely by $\mathrm{NaBH}_{4}$, we use XPS to check the resulting Au nanoparticles. From the XPS spectrum (not shown here), we find that the peaks of zero valence $A u 4 f_{7 /}$ 2 and $\mathrm{Au} 4 \mathrm{f}_{5 / 2}$ of $\mathrm{Au}$ nanoparticles could be detected at 84.6 and $88.2 \mathrm{eV}$. Using $\mathrm{NaBH}_{4}$ as reductant can lead to completely reduced $\mathrm{Au}$ nanoparticles from $\mathrm{AuCl}_{4}{ }^{-}$. Initially, we tried to use mercaptopropyltriethoxysilane (MPTS) to be the functional group and tried to load $\mathrm{Au}$ in the same way. However, the resulting Au@ MCM-41 gives XPS peaks at 86.4 and 90.1. This shows that mercapto functional group interacts with $\mathrm{Au}$ too strongly to allow complete reduction to $\mathrm{Au}(0)$ where the APTS functionalized sample does give metallic gold. Therefore, we did not investigate further the MPTS functionalized mesoporous system.

According to previous reports, for the $\mathrm{CO}$ oxidation catalysis system, the optimum size of Au nanoparticles is around $3 \mathrm{~nm}$ [3-5]. So far the smallest size of uncalcined $\mathrm{Au}$ nanoparticles, we can make in this modification method is about $2 \mathrm{~nm}$ (Fig. 2A). It is also worth noting that there is little gold on the external surface. Most of the loaded $\mathrm{Au}$ catalysts are confined in the nanochannels of MCM- 41 . However for the uncalcined catalyst, its $\mathrm{CO}$ oxidation activity is nearly zero. That is because that the more organic groups are around the Au nanoparticles' surface, the harder it is for the reactants, $\mathrm{CO}$ and $\mathrm{O}_{2}$, to penetrate and contact the catalyst, Au nanoparticles.

We then removed the organic functional group by calcination. It is the simplest method to remove the organic group on $\mathrm{Au}$ nanoparticles. However, the disadvantage of using calcinations is that there may be some oxidations occurring on the surfaces of $\mathrm{Au}$ nanoparticles. After calcinations, we further treated the Au nanoparticles with flowing mixed $\mathrm{H}_{2}$ and $\mathrm{N}_{2}$ gases. There is some sintering of the Au nanoparticles in MCM-41 material and they grow a little bigger. Apparently, many of the nanoparticles are

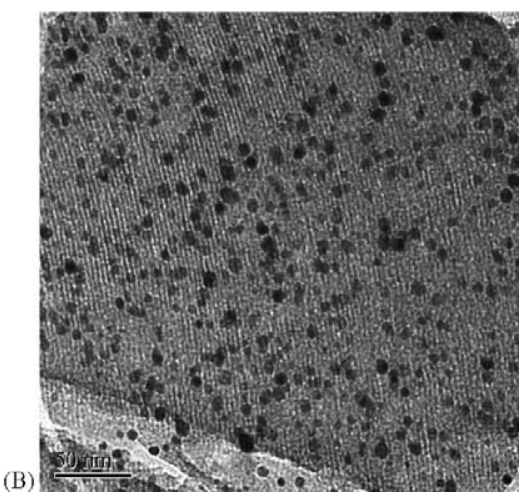

Fig. 2. TEM of MCM-41 modified with APTS, then $\mathrm{AuCl}_{4}{ }^{-}$adsorbed, and reduced by $\mathrm{NaBH}_{4}(\mathrm{~A})$ uncalcined; $(\mathrm{B})$ calcined at $560{ }^{\circ} \mathrm{C}$. 

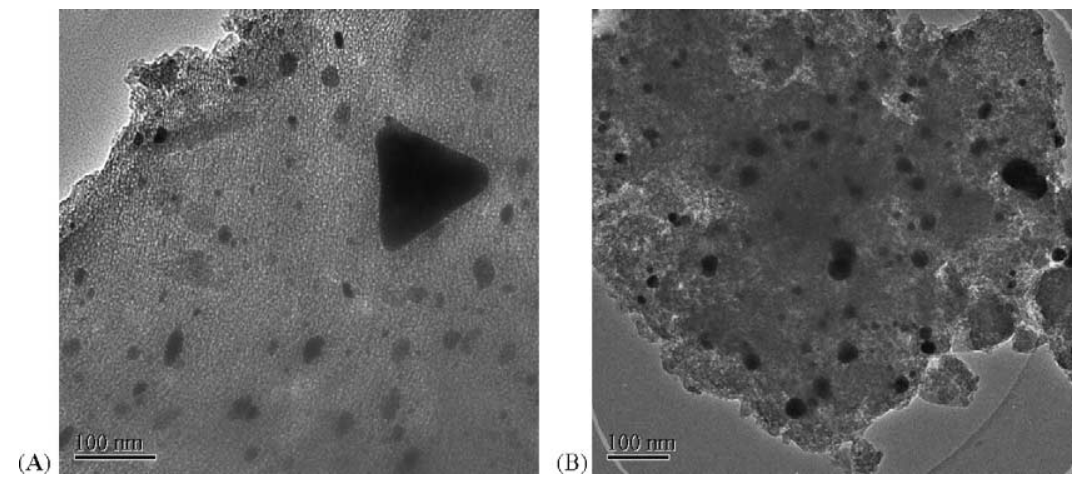

Fig. 3. TEM of MCM-41 without modification, then $\mathrm{AuCl}_{4}{ }^{-}$adsorbed, reduction by $\mathrm{NaBH}_{4}$, calcined at $560{ }^{\circ} \mathrm{C}$.

bigger than the channel diameter. From the transmission electron micrograph (TEM) of Au nanoparticles in Fig. 2B, one can see that the average size of $\mathrm{Au}$ nanoparticles increased to $5.1 \mathrm{~nm}$. The wall thickness of MCM-41 is apparently too thin $(\sim 1.0 \mathrm{~nm})$ to prevent sintering of gold. Fortunately, the increase in size is not substantial; the $\mathrm{Au}$ nanoparticles are still well confined among the pores of this mesoporous silica

In order to compare the host porous materials, we also prepared Au@MCM-41 using un-modified MCM-41. Using calcined MCM-41 silica to adsorb the $\mathrm{AuCl}_{4}{ }^{-}$solution, we find the rate of adsorption is much lower than that of modified mesoporous silica. Then we use $\mathrm{NaBH}_{4}$ as the reductant and follow the same procedure to obtain reduced Au nanoparticles. From the TEM micrograph in Fig. 3, we can find that the particles are much bigger than those we made in the surface modification method.
Besides MCM-41, MCM-48 and SBA-15 were also used as the support to prepare $\mathrm{Au}$ nanoparticle in the same process: e.g. modification of APTS, adsorption of $\mathrm{AuCl}_{4}{ }^{-}$, then reduction with $\mathrm{NaBH}_{4}$. From Fig. 4, we can find that most of the $\mathrm{Au}$ nanoparticles are confined among the channels, although there are some big particles $(>10 \mathrm{~nm})$ on the external surface. The calcination made the $\mathrm{Au}$ nanoparticles aggregate and sinter somewhat; the average size of particles confined in the MCM- 48 channel is $6.9 \mathrm{~nm}$. The particle size of Au in MCM-48 is a little bigger than that of MCM-41, although the pristine MCM-48 has a smaller pore size. This may be due to the weaker pore wall of MCM48 so the growing Au particle can break the wall more easily. This could also explain why the sizes of Au nanoparticles are less uniform in MCM-48. Interestingly, most of the $\mathrm{Au}$ nanoparticles in the SBA-15 mesoporous silica are confined within single channel (Fig. 5). The average particle size is
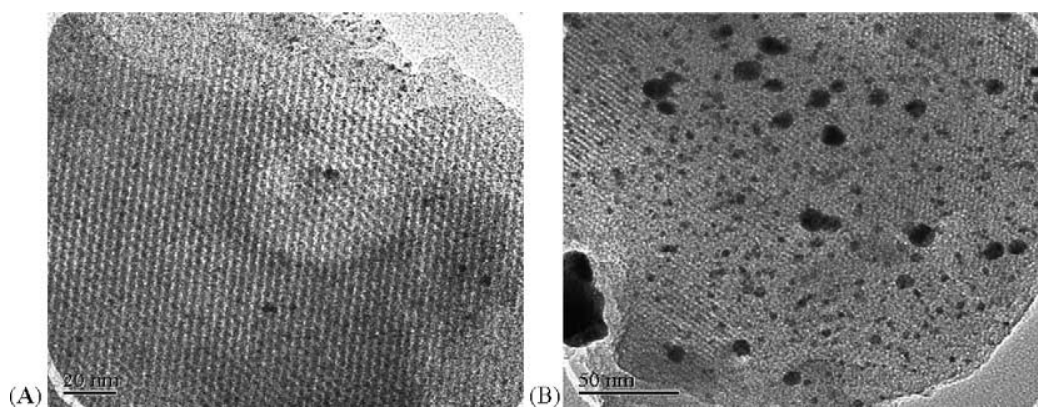

Fig. 4. TEM of MCM-48 modified with APTS, then $\mathrm{AuCl}_{4}{ }^{-}$adsorbed, reduction by $\mathrm{NaBH}_{4}$ (A) uncalcined; (B) calcined at $560{ }^{\circ} \mathrm{C}$.
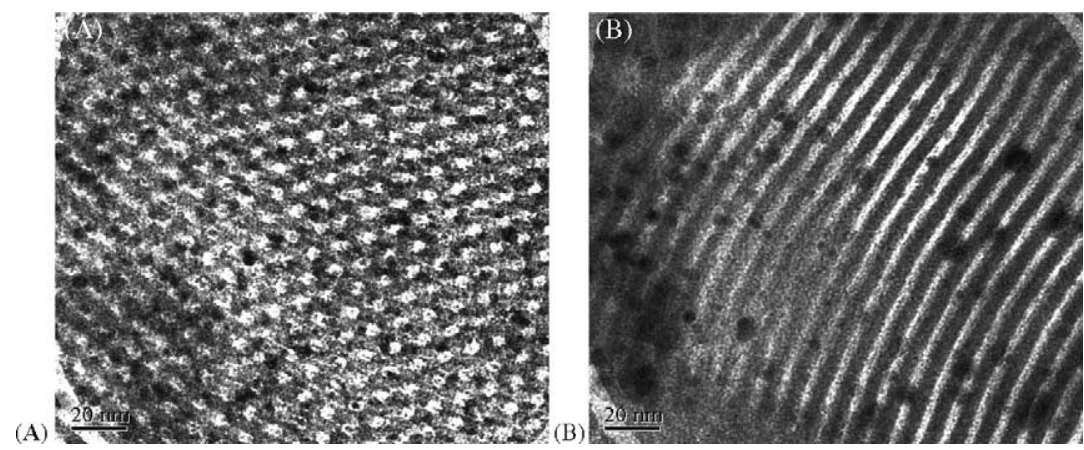

Fig. 5. TEM microgragh of SBA- 15 modified with APTS, then $\mathrm{AuCl}_{4}{ }^{-}$adsorbed, reduction by $\mathrm{NaBH}_{4}$. (A) uncalcined; (B) calcined at $560{ }^{\circ} \mathrm{C}$. 

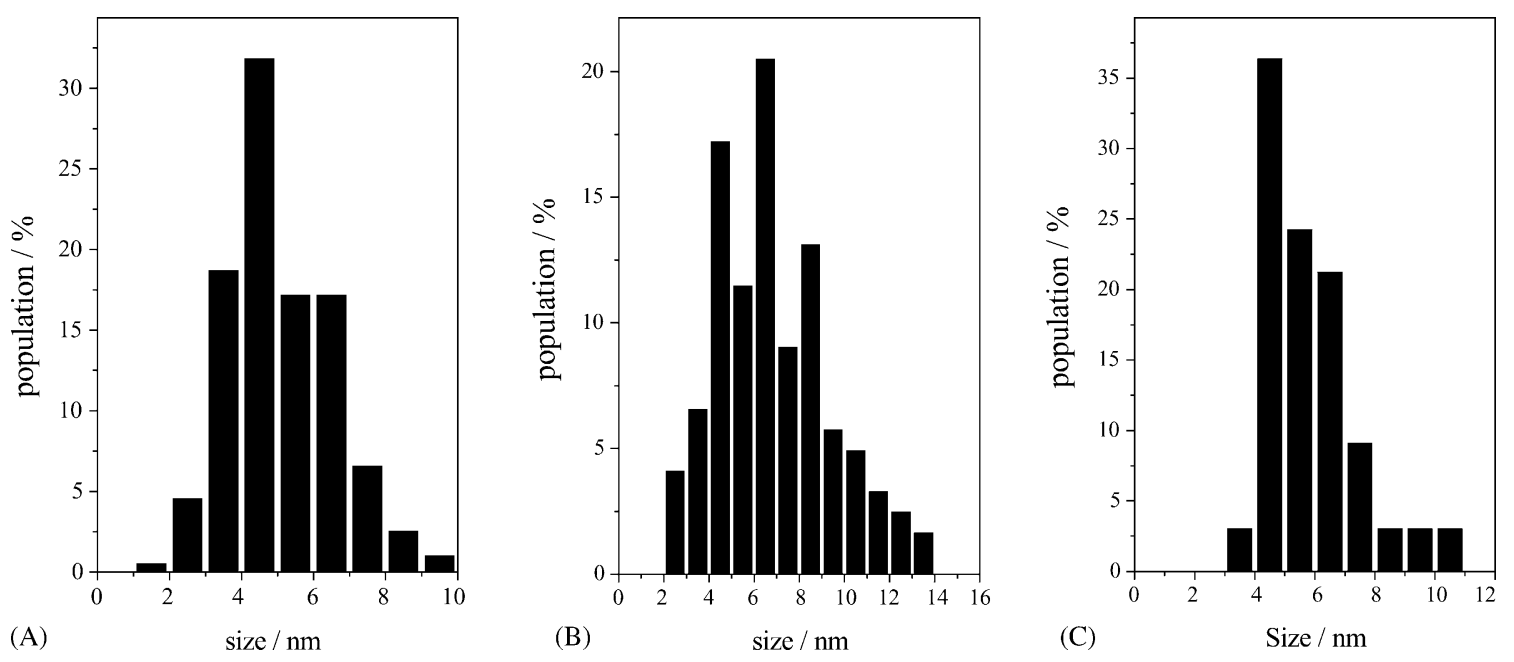

Fig. 6. Size distribution of Au nanoparticles in mesoporous silica modification of $\mathrm{APTS}, \mathrm{AuCl}_{4}{ }^{-}$adsorbed, reduction by $\mathrm{NaBH}_{4}$, then calcined at $560{ }^{\circ} \mathrm{C}$. $(\mathrm{A})$ MCM-41; (B) MCM-48; (C) SBA-15.

$5.8 \mathrm{~nm}$, close to the pore size of SBA-15(5.5 nm). It seems that the thicker pore wall of SBA-15 is able to confine Au particles more tightly within its nanochannels. Fig. 6 shows the size distribution of Au nanoparticles confined among the mesopores of the three mesoporous silicas, from extensive TEM observations. We have excluded some large particles

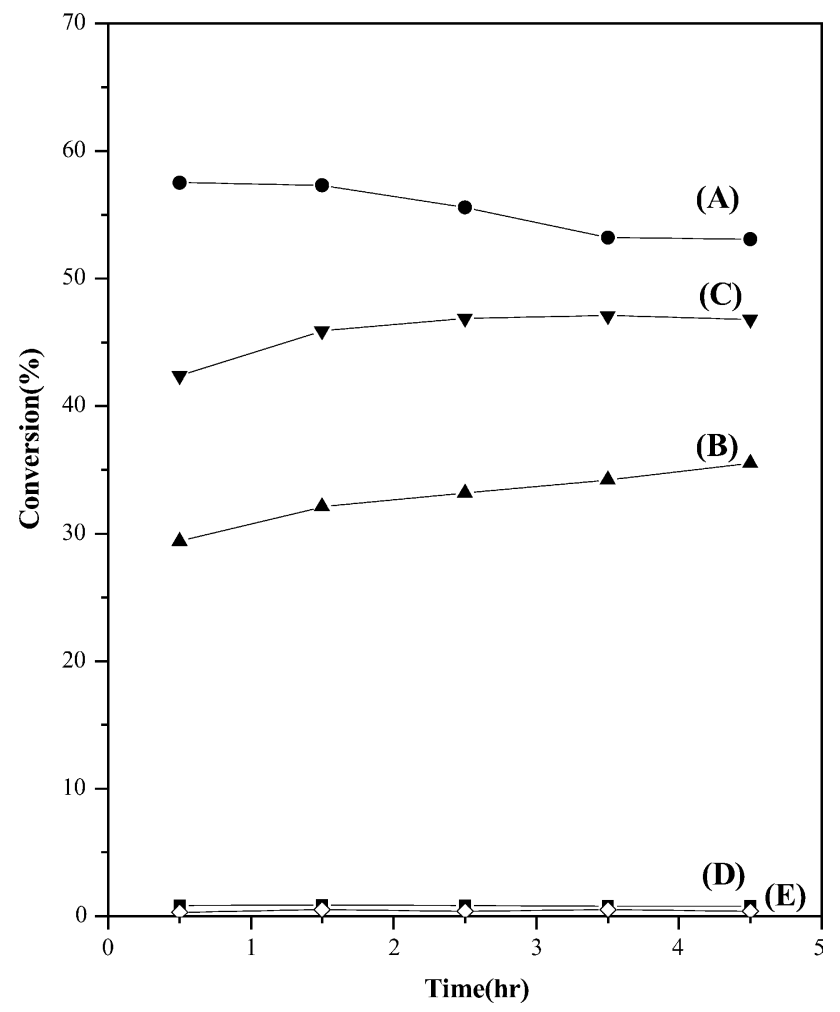

Fig. 7. $\mathrm{CO}$ conversion percentage of the mesoporous silica containing $\mathrm{Au}$ nanoparticles: (A) MCM-41 without organic group, (B) MCM-48 without organic group, (C) SBA-15 without organic group, (D) MCM-41 containing organic group and (E) Au-nanoparticle containing MCM-41 prepared by DP method. The reaction conditions: feed gas $1 \% \mathrm{CO}$ weight balanced with air, $T=80^{\circ} \mathrm{C}$ and WHSV $=9 \times 10^{4} \mathrm{ml} / \mathrm{h} \mathrm{g}$. in MCM-48 judged to be on the external surface of the materials. The average sizes of the Au nanoparticles follow the order: MCM-41 $(5.1 \mathrm{~nm})<$ SBA-15 $(5.8 \mathrm{~nm})<$ MCM$48(6.9 \mathrm{~nm})$.

We then discuss the catalytic activities of the three $\mathrm{Au} @$ mesoporous silica systems for CO oxidation. Fig. 7 shows that all the Au@mesoporous silicas, with the same Au-loading of $4 \mathrm{wt} . \%$, have the capability to catalyze the $\mathrm{CO}$ oxidation reaction at $80{ }^{\circ} \mathrm{C}$. The relatively high conversion $(\sim 57 \%)$ in CO oxidation of our treated Au@MCM-41 catalyst may be due to the small size of Au nanoparticles $(5.1 \mathrm{~nm})$ (Fig. 7A). The steady state CO oxidation activity of Au@SBA-15 (size $5.8 \mathrm{~nm}$ ) is 46\% (Fig. 7B). On the other hand, the conversion of $\mathrm{CO}$ oxidation for the largest particle, $\mathrm{Au} / \mathrm{MCM}-48(6.9 \mathrm{~nm})$, is $35 \%$ (Fig. 7C). The smaller is the size of Au-nanoparticles, the higher the $\mathrm{CO}$ oxidation activity that appears. When the surface functional group APTS is not removed, its CO oxidation conversion is zero (Fig. 7D). This is because the many organic groups around the Au nanoparticles surface prevent the surface of Au from being exposed. We also used the traditional DP method to prepare the mesoporous silica containing Au nanoparticles; we get bigger sizes and more disordered shapes of $\mathrm{Au}$ nanoparticles. With the same activation process for the catalyst, we find that its $\mathrm{CO}$ oxidation activity is almost nil (Fig. 7E) at $80^{\circ} \mathrm{C}$. This is consistent with literature results that $\mathrm{Au}$ deposited on pure silica by DP method has no catalytic activity until a much high temperature, above $200{ }^{\circ} \mathrm{C}$.

\section{Discussion}

The size effect in Au-catalyzed $\mathrm{CO}$ oxidation is an outstanding problem in catalysis [4,33-35]. It is known that there is an optimum size for $\mathrm{CO}$ oxidation of $\mathrm{Au}$ nanoparticles around $3 \mathrm{~nm} \mathrm{[3-5].} \mathrm{However,} \mathrm{the} \mathrm{underlying}$ 
physical chemistry is not clear yet. A substantial complication arises from the strong effect from the support $[7,8]$. The method for deposition of Au nanoparticles and the kind of oxide used as support affect the catalytic activity. Using standard preparation methods, such as precipitation or impregnation, to deposit $\mathrm{Au}$ nanoparticles on various supports, researchers found that catalytic oxidation of $\mathrm{CO}$ with $\mathrm{Au}$ nanoparticles supported on silica is usually not effective. This because the negative charged silica surface is not compatible with the anionic $\mathrm{AuCl}_{4}{ }^{-}$. Okumura et al. [26] were able to produce Au catalyst on silica by CVD method; this gives excellent activity with a half-conversion temperature as low as $227 \mathrm{~K}$. This result shows that the catalyst-support interaction is not really important in determining its activity, as far as silica support is concerned. Yang et al. [23] functionalized SBA-15 with a positively charged group to adsorb $\mathrm{AuCl}_{4}^{-}$and obtained $\mathrm{Au}$ nanoparticles by reduction. They tested the catalyst system with $\mathrm{CO}$ oxidation. Since they did not remove the organic coating, the Au catalysts are well isolated from the wall. So support-catalyst interaction is improbable. Recently, it was argued that of the many factors affecting gold's catalytic activity, the particle size seems to be the dominating one while catalyst-supported interaction seems to be secondary [36]. In this research, we were able to prepare highly active and stable Au nanocatalysts supported on MCM-41 silica. The activity of our catalyst is comparable to the best previously reported Au catalyst. We believe that the silica support does not play an active role in $\mathrm{CO}$ oxidation. Thus the difference in catalytic activities in the three mesoporous support systems reported in this paper may be ascribed to a size effect. In our experiment, we are limited to only three pore sizes. The initial conversion indeed follows the trend in size: e.g. $58 \%$ at pore size $5.06 \mathrm{~nm}, 42 \%$ at pore size $5.78 \mathrm{~nm}$ and $29 \%$ at pore size $6.85 \mathrm{~nm}$. The initial reaction rates are $7.0 \times 10^{-3}, 5.2 \times 10^{-3}$ and $3.6 \times 10^{-3} \mathrm{mmol} \mathrm{g}_{\mathrm{cat}} \mathrm{s}^{-1}$, respectively. These are comparable to catalytic activities observed in silica-supported Au nanocatalyst prepared by CVD, the best catalyst on silica so far [26].

Although we have only three sizes in Au nanoparticles, it is useful to compare the size effect on catalysis here. If one disperses equal amounts of Au into various sizes, and the active site is simply the exposed surface area, the specific activity would be inversely proportional to the diameter of Au nanoparticles $(\sim 1 / \mathrm{d})$. On the other hand, if the active site is the corner site, the specific activity would be $\sim 1 / \mathrm{d}^{3}[36]$. Our data seems to give a size trend somewhere in between the above two cases $\left(\sim 1 / \mathrm{d}^{2}\right)$. Since our Au nanoparticles are still not uniform and the size range is not large, we could not conclude further about the nature of the active site. Further studies are in progress to prepare uniform and smaller sizes of Au nanoparticles.

It should be noted that the high temperature pre-treatment process of the catalyst is important for good catalytic activity. Martra et al. [29] prepared silica-supported Au nanoparticles from $\mathrm{Au}\left(\mathrm{PPh}_{3}\right)_{3} \mathrm{Cl}$. These particles became catalytically active in the $\mathrm{CO}$ oxidation reaction after treatment in $\mathrm{O}_{2}$ at $673 \mathrm{~K}$, which also resulted in a slight sintering of the metal phase. By subsequent heating in $\mathrm{H}_{2}$ at $673 \mathrm{~K}$, the particles became more active in the catalytic reaction. In our experiment, because of the even higher temperature needed for calcinations, the sintering of gold would have been even more severe. Fortunately, at particle sizes of 5-7 nm, we can still observe a high reaction rate. If mesoporous silica that has a thicker wall (such as $\sim 3 \mathrm{~nm}$ in SBA-15) and narrower diameter can be found, the materials may be strong enough to prevent the sintering and lead to smaller Au. Still higher catalytic activities may then be expected. Previously, Dai and co-workers [16] made Au nanoparticles confined within the nanopores after amine-complexation and chemical reduction. They were able to extract the surfactant while preserving the sizes of $\mathrm{Au}$ nanoparticles (less than $3 \mathrm{~nm}$ ) at low temperature. However, the strong binding amino ligand group was not removed and no catalysis test was performed. Yang et al. found that their $\mathrm{Au}$ catalyst is active at room temperature in the $\mathrm{CO}$ oxidation [31]. But their catalytic activity $\left(2.7 \times 10^{-4} \mathrm{mmol} \mathrm{g}_{\text {cat }}^{-1} \mathrm{~s}^{-1}\right)$ is lower than what was observed in the CVD-prepared catalyst [26] and what we observed here. They noted that their Au@SBA-15 catalyst may be somewhat obstructed by the presence of organic coating and thus be less active.

Our previously developed mesoporous silica-supported gold catalyst was prepared by direct incorporation of CTAB-protected Au nanoparticles [22]. Compared with those results, the catalytic activities reported in this work are indeed higher. This is due to the fact that the $\mathrm{Au}$ nanoparticles are bigger in the direct method because of the 'softer' as-synthesized silica wall and the resulting higher degree of sintering. Further researches to prepare uniformly confined Au nanocatalysts of smaller size are desirable.

Finally, we should note that the mesoporous silica might not be a completely inert support. Recently, there are new reports about the substantial effect of water vapor on $\mathrm{CO}$ oxidation catalyzed by gold supported on silica [37,38]. Although we have dried our reactant stream to a water vapor less than $4 \mathrm{ppm}$, its effective concentration inside the hydrophilic nanochannel is uncertain. Moreover, Haruta and co-workers [38] have proposed the surface silanol groups $\mathrm{OH}$ could be involved in the generation of active oxygen species, which can then react with $\mathrm{CO}$. How these new factors play their roles in the Au-catalyzed oxidation are topics to be studied intensively in the near future. The use of mesoporous silica as support may offer new advantages in that the local chemical environments inside the channel system can often be finely controlled by surface functionalization techniques [13].

\section{Conclusions}

We have succeeded in making Au nanoparticles that are embedded within three mesoporous silicas. We then studied 
their catalytic effects on $\mathrm{CO}$ oxidation. The following conclusions have been derived.

Solution adsorption of the gold precursor $\mathrm{AuCl}_{4}{ }^{-}$is much enhanced by surface functionalization by amino group by APTS. Chemical reduction leads to confined nanoparticles of gold in mesoporous silica. This technique is the first example in which gold nanoparticles can be deposited on $\mathrm{SiO}_{2}$ from aqueous $\mathrm{HAuCl}_{4}$ solution, because usually $\mathrm{AuCl}_{4}{ }^{-}$anion does not adsorb on the $\mathrm{SiO}_{2}$ surfaces.

The catalystsAu@mesoporous silica may be activated for $\mathrm{CO}$ oxidation reaction by calcinations and hydrogen reduction. Even though the catalyst samples were calcined and reduced at relatively high temperatures, 560 and at $600{ }^{\circ} \mathrm{C}$, respectively, the catalytic activities for $\mathrm{CO}$ oxidation were high. Gold nanoparticles highly dispersed in mesoporous silica are active for $\mathrm{CO}$ oxidation at a low reaction temperature of $80{ }^{\circ} \mathrm{C}$. The excellent dispersion is probably because coagulation of gold nanoparticles could be depressed by their being confined in the mesopores.

The catalytic activities for $\mathrm{CO}$ oxidation at $80{ }^{\circ} \mathrm{C}$ increases with decreasing sizes of the $\mathrm{Au}$ nanoparticles. For $\mathrm{CO}$ oxidation activity, catalyst-support interaction does not seem to be a ruling factor. The trend in size may be understood mainly as a size effect.

\section{Acknowledgements}

This work was supported from the Program of Academic Excellence sponsored by the Ministry of Education, Taiwan. Prof. B.Z. Wan and Dr. A.Q. Wang have been helpful in discussions of this work. J.H. Wang is thanked for his help in making the XPS measurement.

\section{References}

[1] V. Ponec, G.C. Bond (Eds.), Catalysis by Metals and Alloys, Elsevier, Amsterdam, 1996.

[2] B. Zhou, S. Hermans, G.A. Somorjai, in: G.A. Somorjai (Ed.), Nanotechnology in Catalysis, vols. 1-2, Kluwer Academic/Plenum Publishers, New York, 2004

[3] M. Haruta, Catal. Today 36 (1997) 153.

[4] M. Haruta, M. Date, Appl. Catal. A: Gen. 222 (2001) 427.

[5] M. Valden, X. Lai, D.W. Goodman, Science 281 (1998) 1647.

[6] J. Jia, K. Haraki, J.N. Kondo, K. Domen, K. Tamaru, J. Phys. Chem. B 104 (2000) 11153.

[7] M.M. Schubert, S. Hackenberg, A.C. van Veen, M. Muhler, V. Plazak, R.J. Behm, J. Catal. 197 (2001) 113

[8] A. Wolf, F. Schüth, Appl. Catal. A: Gen. 226 (2002) 1.
[9] H. Liu, A.I. Kozlov, A.P. Kozlova, T. Shido, K. Asakura, Y. Iwasawa, J. Catal. 185 (1999) 252.

[10] L.M. Bronstein, Top. Curr. Chem. 226 (2003) 55.

[11] C.T. Kresge, M.E. Leonowicz, W.J. Roth, J.C. Vartuli, J.S. Beck, Nature 359 (1992) 710.

[12] H.P. Lin, C.Y. Mou, Acc. Chem. Res. 35 (2002) 927.

[13] Y.H. Liu, H.P. Lin, C.Y. Mou, Langmuir 20 (2004) 3231.

[14] M. Okumura, S. Tsubota, M. Iwamoto, M. Haruta, Chem. Lett. (1998) 315.

[15] A. Ghosh, C.R. Patra, P. Mukherjee, R. Kumar, M. Sastry, Micropor. Mesopor. Mater. 58 (2003) 201.

[16] H. Zhu, B. Lee, S. Dai, S.H. Overbury, Langmuir 19 (2003) 3974.

[17] L. Guczi, G. Peto, A.B.K. Frey, O. Geszti, G. Molnar, C. Daroczi, J. Am. Chem. Soc. 125 (2003) 4332.

[18] M.M. Schubert, V. Plzak, J. Garche, R.J. Behm, Catal. Lett. 76 (2001) 143.

[19] B. Zhou, S. Hermans, G.A. Somorjai, G.A. Somorjai (Eds.), Nanotechnology in Catalysis, vol. 1, Kluwer Academic/Plenum Publishers, New York, 2004, p. 313.

[20] B. Zhou, S. Hermans, G.A. Somorjai, G.A. Somorjai (Eds.), Nanotechnology in Catalysis, vol. 1, Kluwer Academic/Plenum Publishers, New York, 2004, p. 111.

[21] W. Chen, W.P. Cai, Z.P. Zhang, L.D. Zhang, Chem. Lett. (2001) 152.

[22] (a) H.P. Lin, Y.S. Chi, J.N. Lin, C.Y. Mou, B.Z. Wan, Chem. Lett. (2001) 1116;

(b) Y.S. Chi, H.P. Lin, J.N. Lin, C.Y. Mou, B.Z. Wan, Stud. Surf. Sci. Catal. 141 (2002) 329; (c) J.H. Liu, Y.S. Chi, H.P. Lin, C.Y. Mou, B.Z. Wan, Catal. Today 93C-95C (2004) 141.

[23] C.M. Yang, M. Kalwei, F. Schüth, K.J. Chao, Appl. Catal. A: Gen. 254 (2003) 289

[24] S.J. Lee, A. Gavriilidis, J. Catal. 206 (2002) 305.

[25] M. Haruta, S. Tsubota, T. Kobayashi, H. Kageyama, M.J. Genet, B. Delmon, J. Catal. 144 (1993) 175.

[26] M. Okumura, S. Nakamura, S. Tsubota, T. Nakamura, M. Azuma, M. Haruta, Catal. Lett. 51 (1998) 53.

[27] For a recent review, see M.-C. Daniel, D. Astruc, Chem. Rev., 104 (2004) 293.

[28] J.-D. Grunwaldt, C. Kiener, C. Wögerbauer, A. Baiker, J. Catal. 181 (1999) 223.

[29] G. Martra, L. Prati, C. Manfredotti, S. Biella, M. Rossi, S. Coluccia, J. Phys. Chem. B 107 (2003) 5453.

[30] Y. S. Chi, Master's Thesis. National Taiwan University, Taipei, Taiwan, 2002.

[31] C.M. Yang, P.H. Liu, Y.F. Ho, C.Y. Chiu, K.J. Chao, Chem. Mater. 15 (2003) 275.

[32] (a) H.P. Lin, L.Y. Yang, C.Y. Mou, S.B. Liu, H.K. Lee, New J. Chem. 24 (2000) 253;

(b) H.P. Lin, Y.H. Liu, C.P. Kao, S.B. Liu, C.Y. Mou, Stud. Surf. Sci. Catal. 135 (2001) 314.

[33] M. Haruta, Chem. Record 3 (2003) 75.

[34] G.C. Bond, Catal. Today 72 (2002) 5.

[35] H. Sakurai, M. Haruta, Catal. Today 29 (1996) 361.

[36] N. Lopez, T.V.W. Janssens, B.S. Clausen, Y. Xu, M. Mavrikakis, T. Bligaard, J.K. Nørskov, J. Catal. 223 (2004) 232.

[37] H.H. Kung, M.C. Kung, C.K. Costello, J. Catal. 216 (2003) 425.

[38] M. Date, M. Okumura, S. Tsubota, M. Haruta, Angew. Chem. Int. Ed. 43 (2004) 2129. 